\section{Mapping Ivorian Continental Shelf Surface Current Using Modis Ocean Color Images: A Maximum Cross Correlation Approach}

Mobio Brice ${ }^{1 *}$, Djagoua Eric ${ }^{1}$, Kouame Adonis ${ }^{1}$, Stewart Bernard ${ }^{2}$, Affian Kouadio ${ }^{1}$ and Robin Marc ${ }^{3}$

\begin{abstract}
Water motion in the Gulf of Guinea is to a certain extent the basis of the pelagic species distribution and on the other hand, is also the pollution vector. The purpose of the study is to thoroughly understand the sea surface current of the Ivorian continental shelf on the local scale. For this study, the Maximum Cross Correlation (MCC) method is applied on chlorophyll concentration data at 1.1 $\mathrm{Km}$ resolution, extracted on selected MODIS satellite imageries acquired from the orbiting AQUA and TERRA satellites and are thereafter filtered to produce an image of composite vectors showing sea surface velocities. The study is made on the four marine seasons of the Ivorian continental shelf. The generated current field map highlights both the eastward Guinea current mainly occurring at the surface and the westward counter-guinea current which generally occurs at a deeper water layer. These apparent simultaneous antagonistic current motions along the coastline occur mainly during the major cold season, the period of transition and the small warm season.
\end{abstract}

\section{Keywords}

Remote sensing; Ocean color; Maximum cross correlation; Surface current: Continental shelf; Ivory Coast

\section{Introduction}

The Ivorian continental shelf hosts important activities that include the industrial fishery, oil exploitation and port exchanges. The fisheries industry is one of the main sources of food provision for the country but not efficient mainly due to lack of knowledge about the physical and biological parameters of coastal marine system. This is illustrated by the improper management the fish species Sardinella Aurita, larvae exploitation during the year 1972 significantly reduced their abundance. As for oil exploitation, it is an activity that plays an increasingly important role but with lots of environmental hazards primarily from discharge of pollutants into the ocean (oil spill off the city of Jacqueville in 2006). When spilled pollutants are not mapped, and their trajectories are not predicted, optimum mitigation measures

\footnotetext{
*Corresponding author: Mobio Brice, Centre Universitaire de Recherche et d'Application en Télédétection (C.U.R.A.T.); Unité de Formation et de Recherche des Sciences de la Terre et des Ressources Minières, Université Félix Houphouët-Boigny; 22 BP 801 Abidjan 22 Côte d'Ivoire, Tel : (225) 22445270; Fax : (225) 22445270; E-mail : mobiobrice@yahoo.fr

Received: February 02, 2013 Accepted: May 04, 2013 Published: May 14
} 2013 to prevent environmental and economic catastrophe cannot be effectively implemented.

In the Gulf of Guinea in general and on the Ivorian continental shelf in particular, the ocean surface current is quantified using in-situ data from oceanographic campaigns which are spatially dispersed. These data unfortunately do not give a synoptic view on currents which has a high spatial and temporal variability pertaining to ocean parameters. The use of remote sensing is in complementary to conventional methods providing high spatial and temporal resolution information at a low cost compared to in-situ measurements. Thus, Hardman-Mountford and McGlade [1] used images of $4 \mathrm{x} 4 \mathrm{~km}$ spatial resolution to study the surface current of the Gulf of Guinea giving a good regional view but no sufficient on a local scale. We then used $1.1 \times 1.1 \mathrm{~km}$ spatial resolution images of chlorophyll concentration to which it apply the Maximum Cross Correlation (MCC) to thoroughly understand the sea surface current of the Ivorian continental shelf on the local scale.

Sea surface temperature (SST) along the ivorian continental shelf is characterized by temperature fluctuations. These temperature variations have allowed to identify four marine seasons [2]: the Small Cold Season (SCS), January to February; the Major Warm Season (MWS), March to June; the Major Cold Season (MCS), July to September and the Small Warm Season (SWS), November to December. Between the MCS and the SWS there is a period of transition which is October month. The study data are collected on all those marine seasons

In the remainder of this paper we present the data and methods used and then expose the results obtained

\section{Main Body}

\section{The maximum cross correlation (mcc) method}

Originally developed for monitoring meteorological clouds [3], the method of maximum cross correlation (MCC) has been successfully applied to thermal $1.1 \times 1.1 \mathrm{~km}$ resolution images for mapping the East Australian current [4], the Gulf Stream [5], the California Current [6] and the coastal waters of British Columbia [7]. Garcia and Robinson [8] well as Tokmakian et al. [6] have successfully calculated the velocities of surface waters by applying the method of MCC to chlorophyll concentrations extracted from images of CZCS (Costal Zone Color Scanner) visible band. Similarly, Crocker [9] and Crocker et al. [10] have successfully applied the MCC method to both temperature and chlorophyll MODIS images of $1.1 \mathrm{x}$ $1.1 \mathrm{~km}$ resolution to describe the ocean surface currents of the coast of California and the Gulf of Mexico.

However, the application of the MCC method to thermal images is inoperable when surface temperature gradients are low, which is common in the equator waters where the Ivorian continental shelf is located. So the images used in this study are images of chlorophyll from MODIS sensors onboard AQUA and TERRA satellite with 1.1 $\mathrm{x} 1.1 \mathrm{~km}$ resolution (NASA Chlorophyll-a concentration (MOD21) 
product). These images (Figure 1) have a greater richness in oceanic frontal structures.

Vectors field generation parameter: The MCC method is a procedure that calculates the displacement of a feature in a small region from one image to another. This procedure cross correlates a template subwindow in an initial image with all possible subwindows of the same size that fall within the search window of a second image. The location of the subwindow in the second image that produces the highest cross correlation with the subwindow in the first image indicates the most likely displacement of that feature. The velocity vector is then calculated by dividing the displacement vector by the time separation between those two images (Figure 2).

The pixel values of the template window are $A(x, y)$, and the corresponding pixels in the second window are $B(x, y)$ at no lag and $B(x+p, y+q)$ for a lag $(p, q)$. The normalized spatial cross correlation function between the template and the search window at lag $(p, q)$ is defined as:

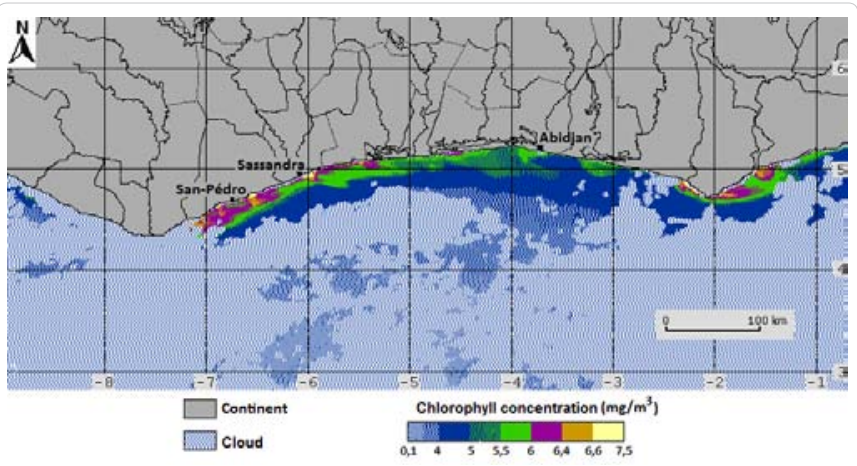

Figure 1: Chlorophyll-a concentration image of 11 May 2005.

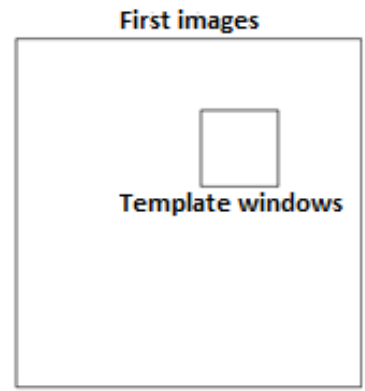

(a)

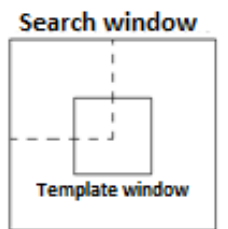

(c)

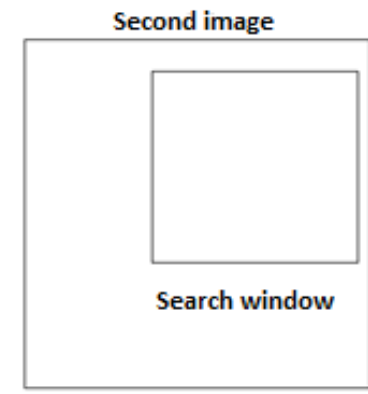

(b)

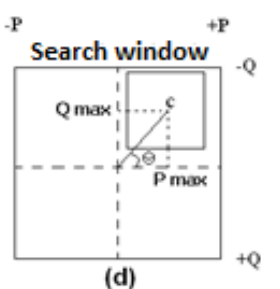

(d)
Figure 2: The Maximum Cross Correlations method (a) template subwindow selected in the first image;

(b) search window selected in the second image;

(c) central point of the search window coincident with central point of the template subwindow;

(d) deplacement $\mathrm{Q}$ max and $\mathrm{P}$ max, corresponding to the region where the correlation is maximum

$$
\begin{aligned}
& r(p, q)=\frac{1}{\sigma A \sigma^{1} B} \Sigma \Sigma\{[A(x, y)-\bar{A}(x, y)] \\
& [B(x+p, y+q)-\bar{B}(x+p, y+q)]\}=\frac{\operatorname{Coy}(p, q)}{\sigma A \sigma^{1} B}
\end{aligned}
$$

The summation is performed over all the $\mathrm{x}$ and $\mathrm{y}$ values ofthe template window. $\bar{A}(x, y)$ and $\bar{B}(x+p, y+q)$ correspond to the mean values of each window. $\operatorname{Cov}(p, q)$ is the covariance of $A$ and $B$ at $\operatorname{lag}(p, q)$, and $\sigma_{A}$ and $\sigma_{B}$ are the standard deviations of the template and lagged window entering the correlation calculation. The displacement $(p, q)$ at the maximum value of the cross correlation determines the advective velocity $c$, as given by the following:

$$
\begin{aligned}
& c=\frac{\left[\left(p_{\max } \Delta x\right)^{2}+\left(q_{\max } \Delta y\right)^{2}\right]^{1 / 2}}{\Delta t} \\
& \theta=\arctan \left(q_{\max } \Delta y / p_{\max } \Delta x\right) .
\end{aligned}
$$

$\Delta x$ and $\Delta y$ represent the spatial interval and the pixel size, respectively, $p_{\max }$ and $q_{\max }$ represent the lag values for the MCC, and $\Delta t$ represents the time interval between both images.

The direction of the motion of the displacement is given by $\theta$, as shown in (3)

The main parameters controlling the MCC method are the minimum and maximum allowable time separation between images, the template subwindow size, and the search window size.

The MCC method is executed from a set of programs. The first of these programs produce current vectors from two successive images of chlorophyll. This program defines a template subwindow of $22 \times 22$ pixels size in the first image. In the second image, it defines a search window of larger size ( $63 \times 63$ or $126 \times 126$ pixels) in which moves the template subwindow to looking for the window that has the maximum correlation with it. Based on the work of Crocker [9] and our personal experience, it appears that the window of $22 \times 22$ pixels $(24.2 \times 24.2 \mathrm{~km})$ is the best window size (minimum size) to contain oceanographic structures and produce coherent vectors.

The search window in the second image must be large enough to accommodate the largest expected velocity in this area which is 0.8 $\mathrm{m} / \mathrm{s}$ as indicated by Lemasson and Et Rebert [11] and Aka [12]. This size is 63 pixels $(69.3 \mathrm{~km})$ for images separated by 24 hours, or 126 pixels $(138.6 \mathrm{~km})$ for images separated by 48 hours. The choice of 48 hours' time separation is motivated by the cloud coverage of the study area which makes difficult obtaining of two cloud-free scenes on two successive days.

The search window is moved in the second image with an overlap of 11 pixels (half the size of the time gate), selected value to ensure that most of any structure which would be spread over two windows $22 \times 22$ pixels is taken into account.

Vector filtering: The second program is used to filter the current vectors to eliminate uncorrelated values. Indeed, the raw file produced by the MCC technique contains many vectors. Some of these vectors do not indicate the real movement of ocean structures and must be eliminated. Vectors eliminated are vectors with low correlation, spatially incoherent neighboring vectors and vectors with very high speed. 
To be valid, any vector must be a high correlation (greater than 0.8 ) and have a velocity less than or equal to a known maximum velocity $(0.8 \mathrm{~m} / \mathrm{s})$. In addition, at least two of eight vectors surrounding the vector involved must have a velocity of up to $0.1 \mathrm{~m} / \mathrm{s}$ more or less than the velocity of the vector involved.

Composite vectors images: After the filtering process is complete, the individual vector fields are composited over a specified period of time to increase the spatial coverage (and to reduce the cloud cover damaging effect) and depict the mean flow.

Validation of results: ADCP (Acoustic Doppler Current Profiler) in-situ surface current data from oceanographic cruises of IFREMER (Institut Français de Recherche pour l'Exploitation de la Mer) were acquired for our results validation.

\section{Results}

\section{Small cold season (SCS) current field}

The figure 3 is the current vector image of February 2007 month. This image showing very little current vectors (due to cloud cover) represents the Small Cold Season (SCS). This figure shows eastward current vectors (which move from west to east).

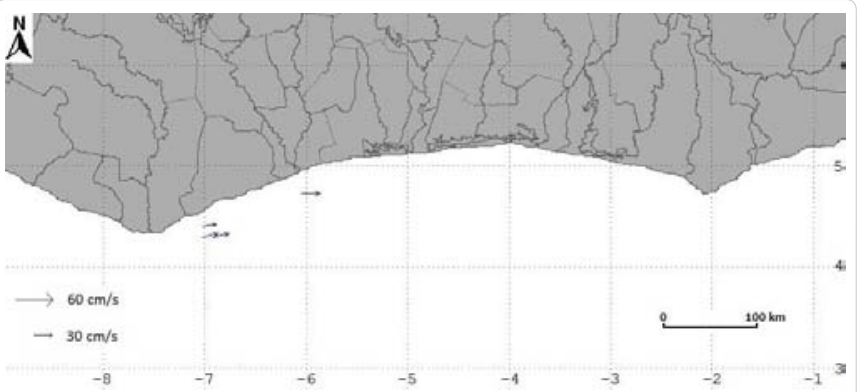

Figure 3: February 2007 vector fields

\section{Major warm season (MWS) current field}

The current vector image of May 2005 (Figure 4) represents the Major Warm Season (MWS). This image shows eastward current vector on the Ivorian continental shelf.

\section{Major cold season (MCS) current field}

On the current vector images of July 2003 (Figure 5) and September 2007 (Figure 6) months which represent the Major Cold Season (MCS) we can observe two groups of current vectors

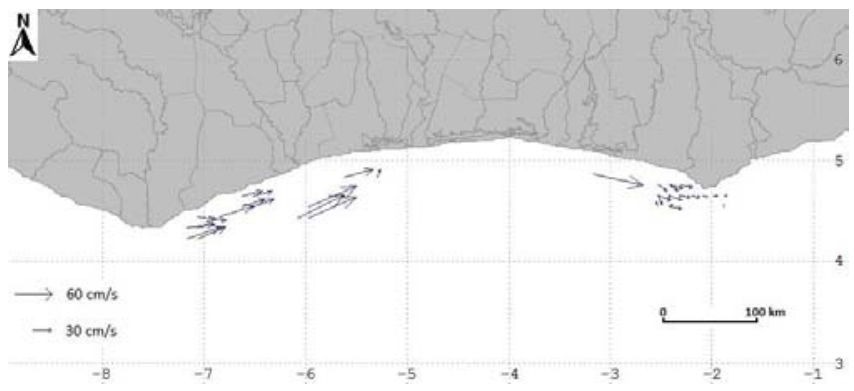

Figure 4: May 2005 vector fields.

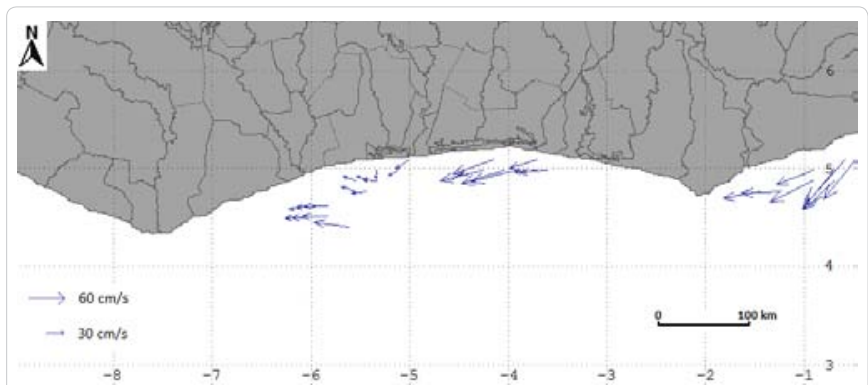

Figure 5: July 2003 vector fields.

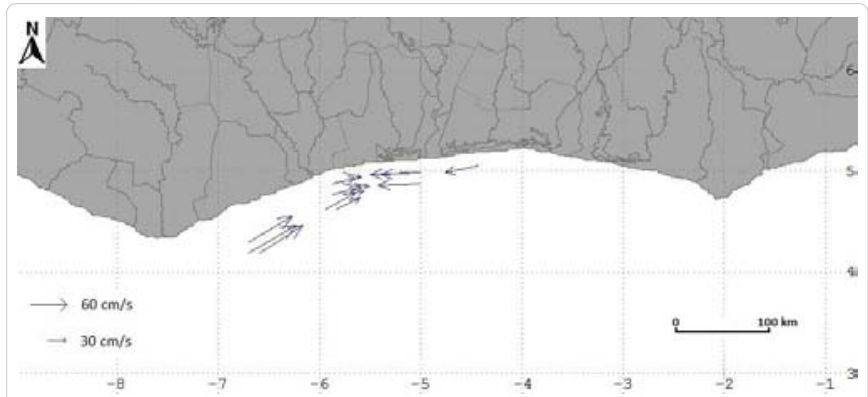

Figure 6: September 2007 vector fields.

that converge on the Ivorian continental shelf surface: One group is constituted by eastward vectors and the other group is constituted by westward vectors.

\section{Period of transition current field}

The representative image of the transition period is October 2009 (Figure 7) current vectors images which shows again two converging groups of current vectors whose one is eastward and other is westward.

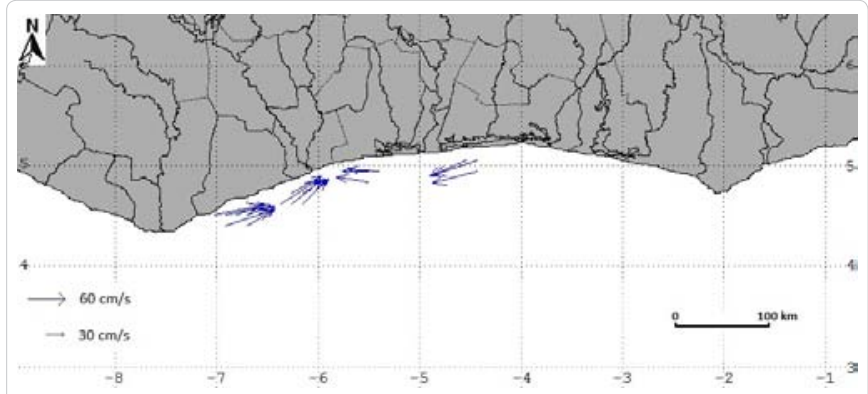

Figure 7: October 2009 vector fields.

\section{Small Warm Season (SWS) current field}

Figure 8 is current vector image of November 2003 which represents the Small Warm Season (SWS). This image show westward current vector at the surface of the ivorian continental shelf.

\section{Results validation}

Acquisition and analysis of ADCP (Acoustic Doppler Current Profiler) in-situ surface current data from oceanographic cruises of IFREMER (Institut Français de Recherche pour l'Exploitation de la Mer) shows the simultaneous presence of the both currents on the surface of the Ivorian continental shelf (Figure 9). 


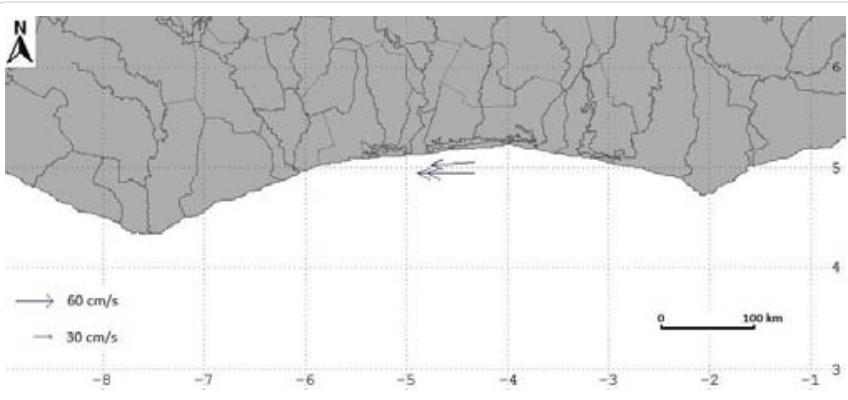

Figure 8: November 2003 vector fields.

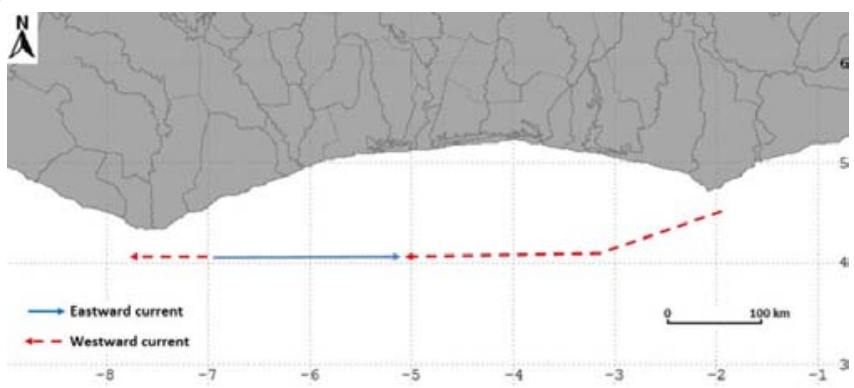

Figure 9: In-situ currents direction from TRCOTON transit from 08 to 23 July 2006.

\section{Discussions}

February 2007 and Mai 2005 Images which represents respectively SCS and MWS shows on the Ivorian continental shelf one eastward surface current that is the Guinea current as described in previous studies $[11,13]$.

Images of July 2003 and September 2007 representing the MCS, image of October 2009 representing the transition period and finally image of November 2003 representing the SWS highlight two converging suface current on the Ivorian continental shelf. The eastward current is the Guinea current and the westward current could be the counter-Guinea current appear here on the surface. Indeed, Lemasson and Et Rebert [11] describe during MCS, TP and SWS the Guinea Current (eastward) to the surface of the Ivorian continental shelf and the counter-guinea current in the subsurface.

Colin et al. [13] describe during these periods at surface eastward current (Guinea current). They also describe at surface westward current (counter-guinea current) much developed in August and September, occupying the entire Ivorian continental shelf in October and November.

Our study could therefore confirm the existence of both the Guinea current and the counter-guinea current at the surface of Ivorian continental shelf during the second half of the year as announced by Colin et al. [13].

\section{Conclusion}

Our study showed that the maximum cross-correlation technique can be apply to ocean color images (chlorophyll concentration) on the Gulf of Guinea in general and in particular on the ivorian coastline to estimate surface currents, despite a very important cloud cover.
It allowed us to estimate coastal surface currents direction during the four marine seasons of the year. A eastward surface current was highlighted. This current is the Guinea current. A westward current surface was also highlighted during the Major Cold Season, the Transition Period and the Small Warm Season. This westward surface current would be the counter-guinea current that is known as manifesting in the subsurface. Thus, our results coupled with insitu data and results of above authors [13] can be hypothesized that counter-guinea current which is usually described as occurring in the subsurface also appear on the surface during the second half of the year. They also show the complexity of ocean circulation on the Ivorian continental shelf particularly from Great Cold Season.

\section{Acknowledgements}

The research leading to these results has received funding from the European Community's Seventh Framework Programme (FP7-SPACE-2009-1) under Grant Agreement No. 242379 for the project Europe Africa Marine Network (EAMNet)

We also wish to express our gratitude to Emery et al. [14] from Colorado Center for Astrodynamics Research (CCAR) at the University of Colorado at Boulder. They have assisted us in the conception of program for extracting chlorophyll concentration, and they have provided us the program for the production of surface current vectors from the technic of maximum crosscorrelation

\section{References}

1. Hardman-mountford NJ, Mcglade JM (2003) Saisonal and interannual variability of oceanographic processes in the Gulf of Guinea: an investigation using AVHRR sea surface temperature data. International Journal of Remote Sensing 24: 3247-3268.

2. Molière A (1970) Marine seasons before Abidjan. Documents Scientific Centre for Oceanographic Research Abidjan 1: 1-15.

3. Leese J, Novak C, Clarke B (1971) An automated technique for obtaining cloud motion from geosynchromus satellite data using cross-correlation. J Appl Meteor 10: 110-132.

4. Bowen MM, Emery WJ, Wilkin JL, Tildesley PC, Barton IJ, et al. ( 2002) Extracting multiyear surface currents from sequential thermal imagery using the maximum cross-correlation technique. J Atmos Oceanic Technol 19: 1665-1676.

5. Emery WJ , Fowler C, Clayson A (1992) Satellite-image-derived Gulf Stream currents compared with numerical model results. J Atmos Oceanic Technol 9: 286-304.

6. Tokmakian R, Strub P, McClean-Padman J (1990) Evaluation of the Maximum Cross-Corralation Method of Estimating Sea Surface Velocities from satellite images. Journal of Atmospheric and Oceanic Technology 7: 852-865.

7. Emery W, Thomas A, Collins M, Crawford W, Mackas D (1986) An objective method or computing advective velocities from sequential infrared satellite images. Journal of Geophysical Research: Oceans 91: 12865-12878.

8. Garcia C, Robinson I (1989) Sea surface velocities in shallow seas extracted from sequential Costal Zone Colour Scanner Satellite Data. Journal of Geophysical Research: Oceans 94: 12681-12691.

9. Crocker RI (2007) Computing Coastal Ocean Surface Currents from Infrared and Ocean Color Satellite Imagery: Methodology, Application, and Analysis. Master of Science Department of Aerospace Engineering Sciences University of Colorado, Boulder, USA.

10. Crocker RI, Matthews D, Emery W, Baldwin D (2007) Computing Coastal Ocean Surface Currents From Infrared and Ocean Color Satellite Imagery. IEEE Transactions on Geoscience and Remote Sensing 45: 435-447.

11. Lemasson L, et Rebert JP (1973) Ocean currents in the Gulf Ivorian. Oceanographic Series, Book ORSTOM 11: 67-95.

12. AKA K (1991) The Quaternary sedimentation on the margin of Côte d'Ivoire: Tests modeling. Thesis Doct Bachelor Sc Nat, Univ Nat Côte d'Ivoire. 
Citation: Brice M, Eric D, Adonis K, Bernard S, Kouadio A, et al. (2013) Mapping Ivorian Continental Shelf Surface Current Using Modis Ocean Color Images: A Maximum Cross Correlation Approach. Geoinfor Geostat: An Overview S1.

13. Colin C, Gallardo Y, Chuchla R, et Cissoko S (1993) Climatic and oceanographic environments on the continental shelf of Côte d'Ivoire.

14. Emery W, Baldwin D, Matthews D (2003) Maximum cross correlation automatic satellite image navigation and attitude corrections for open ocean image navigation. IEEE Transactions on Geoscience and Remote Sensing 41: 33-42.
15. Emery W, Matthews D, Baldwin D (2005) Mapping Surface Currents with Satellite imagery and Altimetry. Environmental Research, Engineering and Management 32: 25-29.

16. Varlet F (1958) The regime of the Atlantic near Abidjan (Ivory Coast). Test coastal oceanography, study eburnie 7: 97-222.

\section{Author Affiliations}

${ }^{1}$ Centre Universitaire de Recherche et d'Application en Télédétection (C.U.R.A.T.) ; Unité de Formation et de Recherche des Sciences de la Terre et des Ressources Minières, Université Félix Houphouët-Boigny ; 22 BP 801 ${ }^{2}$ Earth Systems Earth Observation, CSIR - NRE, Centre for High

Performance Computing, 15 Lower, Hope Street, Rosebank, Cape Town 7700 , South Africa

${ }^{3}$ LETG (UMR 6554 CNRS), Laboratoire Géolittomer, Institut de Géographie et d'aménagement régional de l'Université de Nantes ; BP 81227, 44312 Nantes cedex 3, France

Submit your next manuscript and get advantages of SciTechnol submissions
* 50 Journals
21 Day rapid review process
1000 Editorial team
2 Million readers
More than 5000 facebogk
Publication immediately after acceptance
- Quality and quick editorial, review processing

Submit your next manuscript at • www.scitechnol.com/submission 